\title{
JOGOS ELETRÔNICOS E EDUCAÇÃO: NOTAS SOBRE A APRENDIZAGEM EM AMBIENTES INTERATIVOS
}

\author{
Elaine Cristine do Amarante Matos, UFS, elaine.matos@ globo.com \\ Michell Angelo Santos Lima, DADV/UFS, michell.aju@gmail.com
}

\begin{abstract}
RESUMO
Os jogos eletrônicos são artefatos digitais que proporcionam entretenimento à maioria das crianças e jovens atualmente. Além de momentos de lazer, estes artefatos proporcionam aprendizados que podem ser úteis para o ambiente escolar na facilitação do processo de ensino e aprendizagem. Nesse sentido, considerando a abrangência da cultura digital na sociedade e a necessidade das práticas pedagógicas acompanharem estes avanços, este trabalho tem como objetivo discutir as potencialidades do uso de games como ambientes interativos para melhoria da aprendizagem de conteúdos escolares. Para tanto, embasamos nossas discussões nas teorias de aprendizagem de Vygotsky e Piaget. Utilizar os games em ambientes de aprendizagem é uma alternativa viável considerando a organização cognitiva dos indivíduos inseridos na cultura digital.
\end{abstract}

Palavras-chave: TIC, games, ambientes interativos

\section{ELECTRONIC GAMES AND EDUCATION: NOTES ON LEARNING INTERACTIVE ENVIRONMENTS}

\begin{abstract}
Electronic games are digital artifacts that provide entertainment to most children and young people today. In leisure time, these devices provide learning that can be useful to the school environment in facilitating the teaching and learning process. In this sense, considering the scope of digital culture in society and the need for pedagogical practices follow these advances, this paper aims to discuss the potential of the games use as interactive environments to improve the learning of school subjects. Therefore, basing our discussions on Vygotsky and Piaget's theories of learning. Using games in learning environments is a viable alternative considering the cognitive organization of individuals inserted in the digital culture.
\end{abstract}

Keywords: TIC, games, interactive environments

\section{1) INTRODUÇÃO}

Nos últimos vinte anos as crianças e os jovens adultos cresceram em um mundo computadorizado, no qual estão familiarizados com o uso de softwares e jogos eletrônicos (GIRARD; ECALLE; MAGNANT, 2013). Este cenário caracteriza a chamada "era digital", na qual as pessoas estão adaptadas ao uso de produtos tecnológicos no seu cotidiano, seja em ambientes profissionais, educativos, domésticos e de entretenimento.

Esta influência da cultura digital também é observada no ambiente escolar, através do crescente uso de Tecnologias da Informação e Comunicação (TIC's) e dos ambientes virtuais de aprendizagem.

Desse modo, há uma necessidade de atualização nas práticas pedagógicas e nos recursos didáticos utilizados no sentido de abordar os conteúdos escolares de uma forma mais prazerosa. 
Nessa direção, propõe-se o uso de games eletrônicos como ambientes interativos de aprendizagem tendo em vista aproveitar as diversas aprendizagem que estes jogos proporcionam e utilizá-las no ensino e aprendizagem de conteúdos escolares.

Este trabalho foi elaborado para embasar pesquisas posteriores sobre aprendizagem por meio de games, assim como o desenvolvimento de jogos sérios com este fim. Para compor este artigo de cunho teórico nos baseamos nas contribuições de Piaget e Vygotsky, com suas teorias de aprendizagem, assim como, em trabalhos que indicam os benefícios da ludicidade para educação. Somado a isso, utilizamos também artigos científicos recentes sobre as contribuições das Tecnologias de Informação e Comunicação (TIC) para o campo educacional, em especial às contribuições dos games.

Para tanto, organizou-se este trabalho da seguinte forma: inicialmente, discutem-se alguns aspectos dos jogos na educação à luz da teoria de Piaget e Vygotsky; em um segundo momento, argumentamos a importância destes jogos eletrônicos para o ensino de conteúdos escolares.

\section{2) JOGOS ELETRÔNICOS NA EDUCAÇÃO}

\section{1) Jogos e educação}

$\mathrm{O}$ uso de jogos na educação vem sendo adotado há muitos anos devido às várias habilidades e estímulos que estes jogos proporcionam, ressaltando-se que este envolve ações ativas das crianças, permite exploração e tem múltiplos efeitos da esfera corporal, cognitiva, afetiva e social (MACEDO, 2000). Essa possibilidade é consequência das formas de pensar e agir características de um bom jogador, sendo bastante semelhantes às exigidas para realizar outras tarefas escolares (KISHIMOTO, 2008, p.14).

Para esta autora, podemos destacar certas atitudes, como ser atento, organizado e coordenar diferentes pontos de vista, uma vez que estas habilidades são fundamentais para um bom desempenho no jogo e que também favorecem a aprendizagem, pois a criança passa a ser mais participativa, cooperativa e melhor observadora. Além disso, a ação de jogar exige realizar interpretações, classificar e operar informações, aspectos que tem uma relação direta com as demandas relativas às situações escolares (KISHIMOTO, 2008, p.14).

Somada a estas características, o jogo favorece o aprendizado a partir do erro e estimula a exploração e a solução de problemas, uma vez que o aluno não se constrange quando se erra (MACEDO, 2000).

Além disto, os jogos podem ser usados numa perspectiva avaliativa. Para tanto, segundo Macedo (2000), é necessário que o docente faça com que o aluno tenha uma atuação o mais consciente e intencional possível, de modo que se o êxito não for alcançado, que este discente aprenda a analisar os diferentes aspectos do processo que o impediram de atingi-lo. Com isso, segundo a autora, frequentemente o aluno é levado a rever sua produção e atitudes, sempre tendo como objetivo melhorar aspectos que se apresentam insuficientes, o que corresponde à avaliação formativa na concepção de Luckesi (1999, p. 165):

"Enquanto o planejamento traça previamente os caminhos, a avaliação subsidia o redirecionamento que venham a se fazer necessários no percurso da ação. A avaliação é um ato de investigar a qualidade dos resultados". 
Vale destacar que o uso de jogos na educação utiliza fundamentos de autores de teorias de aprendizagem amplamente difundidas e utilizadas no cenário educacional atual, tais como Piaget e Vygotsky.

\section{2) A teoria psicogenética e os games}

Para Piaget, o nosso mundo, seria o resultado da forma como manipulamos os estímulos do meio e como entendemos o resultado desta manipulação. É como se a cada nova proposta do ambiente reformulássemos o que conhecemos. Sendo assim, Piaget acreditava na importância de estimular a criança a explorar o mundo. Para ele, a educação deveria ser feita de forma ativa, para que o aluno descobrisse como as coisas aconteciam, pois isto favoreceria o desenvolvimento cognitivo (NUNES, 2007).

No que concerne à aprendizagem, a teoria psicogenética explica que, desde pequeno, o homem faz leituras sensoriais do ambiente. Essas leituras são simples, e o resultado delas são os esquemas, registros simples que permitem a criança reconhecer o meio onde vive. Esses esquemas possibilitam à criança reconheça eventos já vivenciados no passado, quando eles se repetem. São estruturas iniciais de organização. Após os dois anos de idade, Piaget acredita que as estruturas cognitivas da criança estão organizadas de forma hierárquica e já permitem o acúmulo de conceitos em categorias, tais como cachorro e gato são peludos, meninos e meninas são seres humanos. A partir daí, Piaget explica a aprendizagem por meio de dois processos: a assimilação e a acomodação (NUNES, 2007).

A assimilação é o esforço que temos para fazer com que os eventos existentes se adaptem ao nosso organismo. Compreendemos os novos conceitos, comparando-os com os que já temos na nossa estrutura. Já a acomodação ocorre quando surge uma situação em que a assimilação não pode ser feita, ocorre o seu complemento, que é a acomodação. Neste caso, ocorre uma adaptação nos conceitos existentes para que se possa assimilar o novo conteúdo. A acomodação sempre acontece quando as informações que vêm do ambiente não correspondem às informações cognitivas já existentes (NUNES, 2007).

Com isso, o equilíbrio cognitivo é restabelecido. Todas as vezes que ocorre um desequilíbrio cognitivo, os processos de assimilação e acomodação passam a funcionar. Esses processos ocorrem durante toda a nossa vida, estamos sempre em processo de desequilíbrio cognitivo em busca de equilíbrio. Esse fenômeno é conhecido como equilibração (NUNES, 2007).

Este processo equilibrador que Piaget chama de equilibração majorante é o responsável pela evolução cognitiva, pelo desenvolvimento mental e pela aprendizagem (aumento de conhecimento, na óptica de Piaget) do sujeito. É através da equilibração majorante que o conhecimento humano é totalmente construído em interação com o meio físico e sociocultural (MOREIRA, 2009).

Devemos nos lembrar de buscar uma linguagem acessível e promover atividades que incentivem a autonomia e a exploração do meio para, desta forma, não contribuirmos com a formação de alunos que só querem receber informações sem saber como desenvolver algo a partir delas.

Outra consequência clara é a do conflito cognitivo. O ensino deve provocar conflitos cognitivos, quer dizer, propor situações para as quais os esquemas dos alunos não funcionem, de modo a provocar a necessidade de construção de novos esquemas. Em termos técnicos, dir-se-ia que o ensino deve conduzir à equilibração majorante e, 
portanto, a aprendizagens. No entanto, se o conflito cognitivo for muito acentuado poderá ocorrer a equilibração minorante, isto é, o aprendiz buscará o equilíbrio cognitivo através da "não aprendizagem", da não modificação ou não enriquecimento de seus esquemas de assimilação. Portanto, a desiquilibração cognitiva é necessária, mas não pode ser tão grande que não leve à equilibração majorante (MOREIRA, 2009).

Portanto, a teoria de Piaget nos mostra a aprendizagem por um enfoque interacionista, ou seja, depende do desenvolvimento orgânico em interação com os estímulos recebidos pelo meio. Para ele, todos os períodos da vida possibilitam novos tipos de conhecimento que formam uma continuidade, partindo da aprendizagem por meio dos sentidos e do movimento, passando pela simbolização, pela manipulação simbólica das quantidades, valores e propriedades dos objetos, até a abstração, previsão e manipulação de todos os tipos de pensamento.

Piaget, em sua obra, analisou o uso do jogo na educação e o desenvolvimento mental do aluno, o que estimulou a adoção destes materiais pedagógicos no ambiente escolar na década de 70 (KISHIMOTO, 2008). Para esta autora, no brincar o sujeito assimila eventos e objetos ao seu eu e suas estruturas mentais, considerando que o comportamento lúdico provém da imitação que representa uma acomodação ao objeto, ou seja, a origem da representação está na imitação (KISHIMOTO, 2008).

Em sua análise, Piaget observou três tipos de sistemas de jogo ao longo do período infantil: de exercício, simbólico e de regras. O primeiro é caracterizado pela repetição de sequências já estabelecidas de ações com finalidade motora; o segundo consiste no aparecimento da representação e da linguagem, no qual as crianças superam a manipulação, assimilando a realidade externa ao seu eu com distorções e transposições; no terceiro, é marcado pela transição do individual para o social, uma vez que a regra pressupõe a interação de dois indivíduos e sua função é regular e integrar o grupo social (KISHIMOTO, 2008).

Nesse sentido da aprendizagem em social, à luz da teoria sócio histórica, os jogos são importantes colaboradores na geração de ZDP (Zona de desenvolvimento proximal), com os quais podemos atingir um nível maior de aprendizado, conforme veremos a seguir.

\section{3) Contribuições da teoria sócio histórica}

Na teoria sócio histórica, Vygotsky explica que o desenvolvimento cognitivo não pode ser entendido sem referência ao contexto social, histórico e cultural no qual ocorre (MORATO, 2002; MOREIRA, 2009).

Para ele, os processos mentais superiores (por exemplo: pensamento, linguagem) do indivíduo têm origem em processos sociais, que no ser humano é mediado por instrumentos e signos construídos social, histórica e culturalmente no meio social em que ele está situado. Na perspectiva de Vygotsky, o desenvolvimento cognitivo é a conversão de relações sociais em funções mentais. Dessa forma, o autor entende que não é através do desenvolvimento cognitivo que o indivíduo torna-se capaz de socializar, é através da socialização que se dá o desenvolvimento dos processos mentais superiores (MOREIRA, 2009). Assim, a educação escolar deve ser vista como uma prática social complexa que tem uma função socializadora (SALVADOR et al, 2000).

Para explicar tal processo, Vygotsky indica as funções psicológicas naturais e as superiores. As naturais, caracterizadas pela atenção, a consciência (noção de estar vivo, 
por exemplo), a memória e as demais funções psicológicas, tais como observamos nos animais, nas crianças pequenas e no homem primitivo, são conhecidas como funções psicológicas naturais, têm origem biológica (você já nasce com elas) e servem para garantir a nossa sobrevivência (NUNES, 2007).

Já as funções psicológicas superiores seriam resultado do desenvolvimento cultural e não do biológico, que, por meio da utilização de instrumentos psicológicos, ocorre uma mediação entre as informações do meio externo com o interno, provocando mudanças na forma de ver e atuar no mundo, acontecendo aí uma interiorização. Quando mudamos algo internamente e, por consequência, mudamos a nossa atuação no mundo, temos um sinal de que aprendemos algo novo. A esse processo, por meio de instrumentos psicológicos que promovem a interação do meio externo com o interno, Vygotsky chamou Mediação Instrumental (NUNES, 2007).

É através da mediação que se dá a internalização (reconstrução interna de uma operação externa) de atividades e comportamentos sócio históricos e culturais. Quer dizer, a conversão de relações sociais em funções mentais superiores não é direta, é mediada e essa mediação inclui o uso de instrumentos e signos (MOREIRA, 2009).

É através da apropriação (internalização) dessas construções sócio históricas e culturais, via interação social, que o indivíduo se desenvolve cognitivamente. Quanto mais ele vai utilizando signos e sistemas de signos, tanto mais vão se modificando, fundamentalmente, as operações psicológicas que ele é capaz.

Assim, ao passo que o sujeito aprende mais instrumentos, tanto mais se amplia a gama de atividades nas quais pode aplicar suas novas funções psicológicas (SALVADOR et al., 2000; MOREIRA, 2009).

A internalização (reconstrução interna) de signos é fundamental para o desenvolvimento humano, mas para isso o ser humano tem que passar a compartilhar significados já aceitos no contexto social em que se encontra, ou já construídos social, histórica e culturalmente. Percebe-se aí a importância crucial da interação social, pois é através dela que a pessoa pode captar significados e certificar-se que os significados que está captando são aqueles compartilhados socialmente para os signos em questão (MOREIRA, 2009).

Nesse sentido, a linguagem é, para Vygotsky, o mais importante sistema de signos para o desenvolvimento cognitivo do ser humano porque o libera dos vínculos contextuais imediatos. Vygotsky é responsável pela hipótese de que a cognição humana individual é constituída "pela interiorização das formas sociais e dialógicas e das interações humanas" (MORATO, 2002, p. 38).

O desenvolvimento dos processos mentais superiores depende de descontextualização e a linguagem serve muito bem para isso na medida em que o uso de signos lingüísticos (palavras, no caso) permite que o indivíduo se afaste cada vez mais de um contexto concreto (SALVADOR et al., 2000). O domínio da linguagem abstrata descontextualizada, flexibiliza o pensamento conceitual e proposicional, desse modo, o desenvolvimento da fala é um marco fundamental no desenvolvimento cognitivo (MOREIRA, 2009).

Quando pensamos em mediação instrumental e interação social podemos visualizar a mediação social, que nada mais é que a Mediação Instrumental ocorrendo de forma interpessoal. Para isto acontecer, é necessário que ocorram atividades práticas e instrumentais em um contexto de interação grupal ou social. Desse modo, a presença e a participação ativa do outro interferem diretamente na aprendizagem (NUNES, 2007). 
É neste contexto que surge um dos principais conceitos de Vygotsky, o de Zona de Desenvolvimento Próximo ou ZDP. A ZDP é a diferença entre a capacidade que a criança tem de resolver algo sozinha (zona de desenvolvimento atual, ZDA) e a capacidade que tem de resolver com a ajuda de alguém. Neste caso, Vygotsky nos mostra que, em grupo, podemos atingir um nível maior de aprendizado (NUNES, 2007).

Quando trazemos este conceito para o ensino, a atividade em grupo é uma boa prática para poder trabalhar a ZDP. Após passar o conteúdo, pede-se aos alunos para formarem grupos que deverão discutir as partes teóricas e resolver as questões. Desta forma, irão utilizar as Mediações Instrumentais, Sociais e a Interiorização. Com isto, a capacidade de aprender aumentará, pois as ideias de um provocarão a reflexão do outro, concordando ou discordando, explorando o máximo de possibilidades até que se chegue a um senso comum. (NUNES, 2007).

É importante destacar que, em outras perspectivas teóricas, o desenvolvimento cognitivo tem sido interpretado como necessário para a aprendizagem, ou tomado quase como sinônimo. Na de Vygotsky, a aprendizagem é que é necessária para o desenvolvimento. Para Vygotsky, o único bom ensino é aquele que está à frente do desenvolvimento cognitivo e o lidera. Analogamente, a única boa aprendizagem é aquela que está avançada em relação ao desenvolvimento. A aprendizagem orientada para níveis de desenvolvimento já alcançados não é efetiva do ponto de vista do desenvolvimento cognitivo do aprendiz (MOREIRA, 2009).

Por fim, para o autor, sem interação social, ou sem intercâmbio de significados, dentro da zona de desenvolvimento proximal do aprendiz, não há ensino, não há aprendizagem e não há desenvolvimento cognitivo. Interação e intercâmbio implicam, necessariamente, que todos envolvidos no processo ensino-aprendizagem devam falar e tenham oportunidade de falar (MOREIRA, 2009).

A teoria de Vygotsky nos traz como principal contribuição à ideia de que, em grupo, o aprendizado é potencializado, pois nos mostra que toda a cultura produzida e aprendida só é possível diante das interações sociais.

Conforme Salvador et al. (2000), Vygotsky usa estudos que envolvem a cognição de seres humanos em comparação com a de outros animais, esclarecendo que a nossa evolução ocorreu a partir da condição de simbolizar e, por conta disto, produzir Mediadores Instrumentais e Sociais, que, ao serem interiorizados, modificam a forma de ver e atuar no mundo.

Estes mediadores e a interiorização formam a base do que ele chamou de Zona de Desenvolvimento Próximo, diferença entre o que se pode realizar sozinho e o que só se pode realizar com a ajuda do outro. Dessa forma, devemos lembrar que vivemos em sociedade e, desta forma, a melhor maneira de se aprender é em grupo (NUNES, 2007).

Portanto, com estes aportes teóricos, discutimos o uso de jogos eletrônicos como recursos de aprendizagem para conteúdos escolares.

\section{3) JOGOS ELETRÔNICOS E APRENDIZAGEM}

A utilização de jogos didáticos em processos educacionais são reconhecidamente recursos didáticos eficazes no ambiente escolar por serem atividades de caráter lúdico, diferente e significativo, apresentando-se como um aliado ao aprendizado. Eles são um recurso alternativo e complementar que pode ser utilizado durante as aulas e desta 
maneira tornar a atividade mais atraente e motivadora, atingindo assim diferentes objetivos simultaneamente (LOPES, 2005; FREITAS et al., 2011).

Somada a estas vantagens, podemos citar as relacionadas ao uso das Tecnologias da Informação e Comunicação (TIC's) na escola. Estes materiais são bastante importantes para o processo de ensino-aprendizagem para diversas matérias de ensino, uma vez que os jovens geralmente não interagem mais com tecnologias passivas e com baixo grau de interatividade (FARDO, 2013b).

A inserção destes materiais tecnológicos sem dúvida cumpre o seu papel motivador em relação aos alunos, uma vez que a novidade é também sempre motivadora. No momento em que se utilizam estes recursos, busca-se uma série de aspectos: motivação para a participação, desenvolvimento da capacidade de observação, aproximação de uma realidade e a fixação da aprendizagem (VARGAS et al., 2007).

Neste universo das TIC's para a educação, destacamos o papel dos jogos eletrônicos educativos. A cultura dos games fornece uma estrutura para se trabalhar problemáticas que envolvem o conteúdo escolar a partir da proposição de situações em que os alunos tenham que empregar os conhecimentos aprendidos. Ao utilizar recursos visuais avançados, como imagens em 3D, recursos de áudio e interfaces interativas, eles aproximam bastante o aluno de situações distantes física e temporalmente (BIZZO, 2012).

Estes jogos já vêm sendo utilizados como recurso didático em diversas áreas de ensino, tais como o ensino de ciências, matemática, linguagens e história, assim como temas transversais propostos nos PCN's, como os que abordam a diversidade cultural brasileira.

Ao considerarmos estes benefícios, aliamos à observação de que a sociedade vê surgir constantemente novas formas de interação mediadas pela aparição de novas interfaces tecnológicas, visto que as pessoas estão cercadas por computadores e smartphones conectados a internet, permitindo-lhes uma comunicação em rede sem precedentes de espaço, tempo e localização, o que vem transformando as formas de relação na sociedade atual do ser humano com o ambiente tecnológico. Neste contexto de ambiente tecnológicos, jogos eletrônicos tem conquistado o público adulto e infantil, uma vez que cerca de 23\% dos brasileiros são jogadores assíduos ou casuais (FARDO, 2013a).

Assim, os jogos de computador mostram-se um ambiente com grande potencial de aprendizagem, visto que estes jogos motivam os alunos por meio do entretenimento em atividades competitivas que incluem regras, metas, feedback, interação e resultados (KIM; PARK; BAEK, 2009).

Nesse sentido, sugerimos o uso de jogos eletrônicos para fins educativos. Inclusive, existe uma área específica à aplicação de games na aprendizagem, chamada de Digital Game-Based Learning (DGBL) que, dentre seus objetivos, está a utilização de jogos comercias para a aprendizagem de conteúdos escolares (FARDO, 2013a). Ainda sobre games, existem os jogos sérios que são elaborados com objetivos específicos, dentre eles os voltados para o ensino.

Os jogos sérios (serious games) são jogos eletrônicos que tem um objetivo além do entretenimento. Para Girard, Ecalle e Magnant (2013), os jogos sérios são vídeo games que apresentam um propósito útil, além da diversão, como por exemplo, para treinamentos, educação, desenvolvimento de habilidades, etc. No entanto, vale destacar que, por serem jogos, eles devem ser, ao mesmo tempo, divertidos e educativos (CARVALHO; ISHITANI, 2013). 
Os "Jogos Sérios" tem como proposta a integração de situações sobre questões levantadas no mundo real para uma forma lúdica e divertida por meio de jogos digitais (COHEN, 2014). A principal diferença entre os jogos sérios e os comuns é a forma como são desenvolvidos, uma vez que desde a concepção ao produto final, os jogos sérios apresentam seus objetivos claramente definidos (GIRARD; ECALLE; MAGNANT, 2013).

Uma das vantagens dos serious games é que eles exploram a tecnologia de Realidade Virtual, e utilizam recursos computacionais específicos que oferece realismo e interatividade em tempo real, a partir da reconstrução de novos conceitos em contextos similares aos do mundo real (MACHADO et al, 2011).

Diante destes diversos objetivos, existem diversos tipos de jogos sérios, tais como jogos de estratégia e treinamento cerebral. Desta forma, pode-se dividir a finalidade destes jogos, em três categorias: conscientização, construção de conhecimentos e treinamento. Na primeira, o jogo tem o objetivo de destacar um novo problema, explorando suas características e apontando as consequências das ações executadas; na segunda, podemse simular situações em que o uso de um conhecimento seja necessário para a evolução no jogo; na terceira, são usados para simular situações críticas que envolvam algum tipo de risco, tomada de decisões ou, ainda, para desenvolver habilidades específicas (MACHADO et al, 2011).

Destarte, os jogos sérios vem sendo utilizados nos ambientes escolares por se tratarem de um recurso didático de ampla aceitação por parte dos alunos, uma vez que estes são sujeitos parte de um cultura que tem estes produtos tecnológicos como artefatos presentes em seu cotidiano.

Ainda neste universo dos jogos eletrônicos, podem-se destacar os jogos do tipo RPG, ou Role Playing Game ou Jogo de Papéis. Estes jogos lidam com o imaginário do jogador, que deve contar e representar histórias (SANTOS; MAROTI, 2013), que através da vivência de um personagem serve como metodologia para promover os vários aspectos de uma situação problema a ser estudada. Assim, os RPG eletrônicos são considerados boas interfaces para a educação, pois possibilitam a inserção em uma simulação da vida real, com desafios, ameaças e perigos.

Ao simular estas situações, estimula-se a interação do aluno com o ambiente que se objetiva ensinar. Para tanto, interagir com um game normalmente envolve estar atento a uma quantidade de variáveis inter-relacionadas e acredita-se que esse meio provoque transformações no sistema cognitivo desses indivíduos (FARDO, 2013b).

É neste contexto que os games são importantes geradores de ZDP (diferença entre a capacidade que a criança tem de resolver algo sozinha e a capacidade que tem de resolver com a ajuda de alguém), partindo do pressuposto que Vygotsky nos mostra que, em grupo, podemos atingir um nível maior de aprendizado (NUNES, 2007).

Quando trazemos este conceito para o ensino, a atividade em grupo é uma boa prática para poder trabalhar a ZDP. Dessa forma, estes ambientes interativos funcionam como mediadores do conhecimento uma vez que através destes jogos é possível proporcionar a interação do aluno com o "outro" da perspectiva de Vygotsky, seja este "outro" de forma virtual (FARDO, 2013b). Isto se dá porque, no contexto sócio cultural que vivemos, a interação social perdeu a conotação presencial, e constantemente é substituída por interações com os artefatos tecnológicos.

Através dos jogos, os estudiosos de Vygotsky focalizam a questão da atividade social, especialmente na interação entre crianças e docentes, tendo em vista que as brincadeiras 
são aprendidas pelas crianças no contexto social, tendo o suporte orientador de profissionais ou crianças mais velhas (KISHIMOTO, 2008, pg 43). Desse modo, para a autora, insere-se a criança no meio social ao interagir e negociar com outros, ao estabelecerem-se compreensões que se tornam conhecimento social construído continuamente. Portanto, a brincadeira se constitui como fonte de desenvolvimento ao criar zonas de desenvolvimento proximal, sendo o jogo o elemento que irá impulsionar o desenvolvimento dentro da zona de desenvolvimento proximal (KISHIMOTO, 2008).

Isto se dá porque os jogos colaboram para emergência do papel comunicativo da linguagem, a aprendizagem das convenções sociais e a aquisição de habilidades sociais (KISHIMOTO, 2008, pg 43), visto que os games tem a capacidade de envolver as pessoas em situações que precisam tomar decisões constantes e obter aprendizado por meio de um raciocínio lógico não linear que são essenciais para ensinar jovens e adultos sobre os problemas sociais, por meio da oferta de um ambiente agradável, seguro e interativo (COHEN, 2014).

Além disso, o desenvolvimento de jogos digitais, frequentemente, é associado ao estímulo de fantasias e brincadeiras para o público infantil e adulto (COHEN, 2014). Para Vygotsky, é importante que no jogo de papéis a criança possa criar uma situação imaginária, incorporando elementos do contexto cultural adquiridos por meio da interação e comunicação (KISHIMOTO, 2008).

\section{CONCLUSÃO}

Ao refletirmos sobre a cultura Digital e suas implicações para o ambiente escolar, é possível observar a necessidade de uma mudança nas práticas pedagógicas para adequar as estratégias didáticas a esta geração de alunos "gamers". Dessa forma, o uso de games em ambientes educacionais é justificado a partir do atual momento histórico e do contexto social e cultural atuais.

Utilizar essas estratégias de modo a aproveitá-las em ambientes de aprendizagem, com o intuito de potencializar o ensino e a aprendizagem, é uma alternativa viável considerando a organização cognitiva dos indivíduos inseridos nessa cultura.

Além de proporcionar experiências e ambientes que não seriam acessíveis no mundo real, os games podem proporcionar no processo de aprendizagem o papel do "outro", conforme a perspectiva de Vygotsky. No entanto, o momento sócio histórico que vivemos, esse outro perdeu a conotação fortemente presencial, no sentido das interações face a face, sendo representado pelas inúmeras interações que os indivíduos realizam com as tecnologias, e aqui essas interações são representadas pelo uso dos games.

No entanto, para a inserção destes recursos didáticos nas salas de aula, é necessário que os docentes saibam como utilizar estes recursos. Antes de utilizar estes materiais, é necessário que o professor avalie estes recursos de acordo com seus objetivos, com a nivelação do conteúdo com a série a ser abordada, com seus alunos, com o ambiente que lhe é disponível, e quando necessário, realizar adaptações. Desse modo, o professor deve ter formação e competência adequadas para avaliação destes recursos.

\section{REFERÊNCIAS BIBLIOGRÁFICAS}

BIZZO, N. Metodologia do ensino de biologia e estágio supervisionado. São Paulo: Ática, 2012. 
VARGAS, S.R.S.; LEMES, A.; BRAGA, A.J.; ARAÚJO, M.M. Usos dos jogos didáticos em sala de aula. IN: SALÃO DE INICIAÇÃO CIENTÍFICA E TRABALHOS ACADÊMICOS, 8, 2007, Guaíba. Anais. Guaíba: Universidade Luterana do Brasil, 2007. P. 1-10.

CARVALHO, R.N.S.; ISHITANI, L. 2013. Fatores motivacionais para desenvolvimento de mobile serious games com foco no público da terceira idade: uma revisão de literatura. Educ. Temat. Digit, v.15, n.1, p. 16-32.

COHEN, E. L. Computers in Human Behavior What makes good games go viral? The role of technology use, efficacy, emotion and enjoyment in players' decision to share a prosocial digital game. Computers in Human Behavior, v. 33, p. 321-329, 2014. Disponível em: http://dx.doi.org/10.1016/j.chb.2013.07.013

FARDO, M.L. 2013 a. A gamificação aplicada em ambientes de aprendizagem. Novas Tecnologias Na Educação, v. 11 n 1. p 1-9.

FARDO, M.L. A gamificação como estratégia pedagógica: estudo de elementos dos games aplicados em processos de ensino e aprendizagem. Caxias do Sul: Universidade de Caxias do Sul, 2013b. Dissertação de mestrado.

FERRARI, A.G.; SORDI, R.O. A dimensão do corpo na aprendizagem. Estilos da Clínica, v. xiv, n. 27, p. 208-229. 2009.

FREITAS, R. DE L., FURLAN, A. L. D., KUNZE, J. C., MACIEL, M. M., SANTOS, A. C. Q. DOS, COSTA, R. R. Uso de jogos como ferramenta didática no ensino de botânica. IN: Congresso Nacional De Educação, 10, 2011, curitiba. Anais... curitiba, 2011.

GIRARD, C.; ECALLE, J.; MAGNANT, A. 2013. Serious games as new educational tools: how effective are they? a meta-analysis of recent studies. Journal of computer assisted learning, n. 29. pg 207-219.

KIM, B.; PARK, H.; BAEK, Y. Not just fun, but serious strategies: Using metacognitive strategies in game-based learning. Computers and Education, v. 52, p. 800$810,2009$.

KISHIMOTO, T.M. O jogo e a educação infantil. São Paulo: Cengage Leraning, 2008. $63 \mathrm{p}$.

LOPES, M. G. Jogos na educação: criar, fazer, jogar. 6 ed. - são paulo, cortez, 2005.

MACEDO, L. Aprender com jogos e situações-problema. Porto alegre: artmed, 2000.

MACHADO, L.S. et al. 2011. Serious games baseados em realidade virtual para educação médica. Rev. Bras. Educ. Med. vol.35 no.2 rio de janeiro abr./jun. 2011.

MORATO, E.M. Linguagem e cognição: as reflexões de L.S. Vygotsky sobre a ação reguladora da linguagem. São Paulo: Plexus editora, 2002.

MOREIRA, M.A. 2009. Comportamentalismo, construtivismo e humanismo. Disponível em: http://www.if.ufrgs.br/ moreira/subsidios5.pdf Acesso em 05jan2015.

NUNES, A.L.V. 2007. Introdução à psicologia da aprendizagem. Disponível em: http://www.cesad.ufs.br/orbi/public/uploadcatalago/16541216022012introducao_a_psic ologia_da_aprendizagem_aula_7.pdf Acesso em 13jan2015.

SALVADOR, C.C. et al. Psicologia do ensino. Porto Alegre: Artes Médicas Sul, 2000. $408 \mathrm{p}$.

SANTOS, E.L.; MAROTI, P.S. Educação ambiental através de meios interativos (EAMI): validação do rpg 'o jogo do parque' junto a diferentes atores sociais do entorno do parque nacional serra de Itabaiana, SE. CONGRESSO NACIONAL DO MEIO AMBIENTE, 10, 2013, Poços de Caldas. Anais. Poços de caldas: Instituto Federal do Sul de Minas Gerais, 2013, P. 1-5. 